\title{
Política de avaliação e performatividade: gerencialismo, biopoder e controle social
}

\section{Resumo}

O objetivo deste artigo é analisar a política de avaliação da educação brasileira que recebeu maior estímulo no contexto reformista do Novo Gerencialismo Público (NGP), cujas bases se encontram na doutrina neoliberal. Tem-se como pressuposto que essa política de avaliação é um dispositivo disciplinar e um instrumento de poder que se submete aos princípios da performatividade, trazendo implicações para a educação e para os agentes educacionais. Metodologicamente, recorre-se à teoria de biopoder de Michel Foucault e ao conceito de performatividade de Stephen Ball. Constata-se que, para além de aferir o desempenho dos estudantes, ao promover o intenso controle social, essa política pública altera a subjetividade dos agentes educacionais, punindo-os e formatando-os, em especial, os docentes.

Palavras-chave: Escolas públicas - Avaliação - Brasil. Controle social. Performatividade. Educação.
Raquel Hissae Nagase

Universidade Estadual de Maringá -

UEM - Maringá/PR - Brasil

raquelnagase@gmail.com

\section{Mário Luiz Neves de Azevedo} (pesquisador CNPq)

Universidade Estadual de Maringá -

UEM - Maringá/PR - Brasil

mlnazevedo@uem.br

\section{Para citar este artigo:}

NAGASE, Raquel Hissae; AZEVEDO, Mário Luiz Neves de. Política de avaliação e performatividade: gerencialismo, biopoder e controle social. Revista Linhas. Florianópolis, v. 22, n. 48, p. 248-266, jan./abr. 2021.

\section{DOI: $10.5965 / 1984723822482021248$}

http://dx.doi.org/10.5965/1984723822482021248 


\title{
Evaluation policy and performativity: managerialism, biopower and social control
}

\begin{abstract}
The objective of this paper is to analyze the evaluation policy of Brazilian education that received the greatest stimulus in the reformist context of the New Public Management (NPM), whose bases are found in neoliberal doctrine. It is assumed that this evaluation policy is a disciplinary tool and an instrument of power that undergoes performativity, bringing implications for education and for educational agents. Methodologically, Michel Foucault's theory of biopower and Stephen Ball's concept of performativity are used. It appears that, in addition to assessing student performance, by promoting intense social control, this public policy alters the subjectivity of educational agents, punishing and shaping them, especially teachers.
\end{abstract}

Keywords: Public schools - Evaluation - Brazil. Performativity. Social control. Education. 
A política de avaliação educacional ganha ênfase no contexto de redefinição do papel do Estado, cujos preceitos neoliberais fundamentam as reformas realizadas. Nesse contexto de reestruturação dos Estados, um novo modo de gestão, inspirado no setor privado, denominado Novo Gerencialismo Público (NGP), passa a materializar-se na esfera pública, e, a política de avaliação atende muito bem aos princípios do NGP.

De acordo com Hood (1991), a descentralização da gestão, a definição de metas e indicadores, preferencialmente, quantitativos; a alocação de recursos e recompensas, vinculadas ao desempenho; a flexibilização e a redução de custos são alguns dos preceitos do NGP. As justificativas são: a necessidade de ênfase nos resultados ao invés dos procedimentos; a competitividade como chave para reduzir custos e melhorar padrões; a necessidade de usar ferramentas eficazes de gerenciamento do setor público; fazer mais com menos (HOOD, 1991). Percebe-se que muitas dessas palavras passaram a fazer parte do dicionário da gestão educacional. Azevedo (2018) observa que, no Brasil, o NGP, paradoxalmente, torna-se referência para reformas do Estado pouco tempo depois da promulgação da Constituição da República Federativa do Brasil, de 1988, revertendo muitas das conquistas inscritas na chamada "Constituição Cidadã",

no Brasil, o NGP surge com força com as reformas administrativas públicas que buscavam maior eficiência nos anos 1990, tento o governo de Fernando Collor de Mello (1990-1992) como pioneiro nas reformas neoliberalizantes, que se efetivou definitivamente nos dois mandatos do Presidente Fernando Henrique Cardoso (1995-2003), tendo permanecido operante mesmo depois da chegada ao poder dos governos de cunho popular de Luiz Inácio Lula da Silva (2003-2011) e Dilma Roussef (20112016). Frise-se que estas reformas, em grande medida incentivadas e influenciadas por organizações internacionais, a exemplo do Banco Mundial, são compatíveis com as várias versões do que se convencionou a chamar de neoliberalismo. (AZEVEDO, 2018, p. 4)

É naquele momento que a avaliação passa a ser inserida no contexto das políticas públicas educacionais, apropriando-se de ferramentas avaliativas, de cunho neoliberal (FREITAS et. al., 2009). Os autores postulam a existência de três níveis integrados e articulados de avaliação da qualidade da educação: em larga escala, em redes municipais e estaduais; institucional, das escolas, realizada pela comunidade escolar; da 
aprendizagem, em sala de aula, sob a responsabilidade do professor. Contudo, a tendência é "se querer fazer da avaliação de sistemas um instrumento da avaliação da sala de aula e da escola" (FREITAS et. al., 2009, p. 65).

A avaliação em larga escala é a que comumente se destaca na política de avaliação da educação brasileira e tem como pressuposto medir o desempenho dos alunos, classificando e divulgando amplamente os produtos das provas padronizadas que são organizadas em forma de rankings pela mídia, como se fossem mercadorias disponíveis, possibilitando assim a livre escolha de pais e alunos. A ideia de livre escolha é defendida pela doutrina neoliberal, que prega relações sociais baseadas no mercado.

Segundo Dardot e Laval (2016, p. 140), o mercado neoliberal não é mais apenas o espaço livre de circulação de mercadorias, como para o liberalismo clássico, mas, é concebido "como um processo de autoformação do sujeito econômico, um processo subjetivo autoeducador e autodisciplinador pelo qual o indivíduo aprende a se conduzir" racionalmente. Nessa direção, quanto mais livre é o indivíduo calculador para escolher, “mais ele deve ser vigiado e avaliado para obter seu oportunismo intrínseco e forçá-lo a conjuntar seu interesse ao da organização que o emprega" (DARDOT; LAVAL, 2016, p. 217). Assim,

A estratégia neoliberal consistirá, então, em criar o maior número possível de situações de mercado, isto é, organizar por diversos meios [...] a obrigação de escolher para que os indivíduos aceitem a situação de mercado tal como lhes é imposta como realidade, isto é, como única regra do jogo, e assim incorporarem a necessidade de realizar um cálculo de interesse individual se não quiserem perder no jogo e, mais ainda, se quiserem valorizar seu capital pessoal num universo em que a acumulação parece ser a lei geral da vida. (DARDOT; LAVAL, 2016, p. 217, grifo dos autores)

Dale (2010) aponta o NGP como a forma política do neoliberalismo que funciona por meio do Estado. Diante disso, ao estar em consonância com os preceitos dessa forma de gestão, a política de avaliação também está em acordo com a doutrina neoliberal. Para Foucault,

O problema do neoliberalismo é, [...], saber como se pode regular o exercício global do poder político com base nos princípios de uma economia de mercado. Não se trata portanto de liberar um espaço vazio, mas de relacionar, de referir, de projetar numa arte geral de governar os 
princípios formais de uma economia de mercado. (FOUCAULT, 2008, p. 181)

Nesse contexto de reformas neoliberalizantes, a avaliação assume uma centralidade nas políticas públicas educacionais, em consonância com os preceitos do NGP. Considerando as características da avaliação em larga escala, entende-se que os efeitos dessa avaliação são o reforço do individualismo e a competição entre os avaliados, sejam os próprios estudantes ou instituições, redes e entes federados, permitindo assim o estabelecimento de mecanismos de controle, inclusive por intermédio de algoritmos, e a responsabilização dos indivíduos (estudantes e docentes) e instituições (escolas).

O objetivo deste texto, portanto, é discutir os propósitos e apontar determinados efeitos desse modo de regulação por intermédio da política de avaliação que envolve provas padronizadas, benchmarking' e publicização dos resultados. Assim, discutimos essa política como um dispositivo disciplinar conforme a teoria de biopoder de Michel Foucault e como um instrumento que altera a subjetividade do próprio ser, segundo Stephen Ball.

\section{Avaliação: um dispositivo disciplinar}

A avaliação como dispositivo de controle social por parte do Estado não é recente, a novidade é que esse controle não se subordina mais, apenas, a uma lógica hierárquica e burocrática, mas articula-se com os mecanismos de mercado educacional (AFONSO, 2007). É nesse contexto que buscamos compreender a avaliação como controle social, do qual o Estado não abre mão.

Com base na teoria do poder de Michel Foucault, Danner (2010) sustenta a ideia de que tanto a anátomo-política do corpo como a biopolítica da espécie foram os dois procedimentos de poder postos em prática pelo Estado moderno, e que têm como tarefa

\footnotetext{
${ }^{1}$ De acordo com Azevedo (2016), benchmarking tem origem nas atividades de topografia e da sapataria artesanal e significa medir a qualidade de algo comparando um padrão. A avaliação baseada nesse método teve início no setor privado nos Estados Unidos na década de 1970. O Ideb é apontado pelo autor como um instrumento de benchmarking.
} 
principal a formatação e o controle do indivíduo e da própria sociedade, respectivamente.

De acordo com Foucault:

Esse bio-poder, sem a menor dúvida, foi elemento indispensável ao desenvolvimento do capitalismo, que só pôde ser garantido à custa da inserção controlada dos corpos no aparelho de produção e por meio de um ajustamento dos fenômenos de população aos processos econômicos. Mas, o capitalismo exigiu mais do que isso; foi-lhe necessário o crescimento tanto de seu reforço quanto de sua utilizabilidade e sua docilidade; foram-lhe necessários métodos capazes de majorar as forças, as aptidões, a vida em geral, sem por isto torná-las mais difíceis de sujeitar; se o desenvolvimento dos grandes aparelhos de Estado, como instituições de poder, garantiu a manutenção das relações de produção, os rudimentos de anátomo e de bio-política, inventados no século XVIII como técnicas de poder presentes em todos os níveis do corpo social e utilizadas por instituições bem diversas (a família, o Exército, a escola, a polícia, a medicina individual ou a administração das coletividades), agiram no nível dos processos econômicos, do seu desenrolar, das forças que estão em ação em tais processos e os sustentam; operaram, também, como fatores de segregação e hierarquização social, [...]. (FOUCAULT, 1985, p. 132-133, grifo do autor)

Se as técnicas de poder naquele momento foram tão importantes para a manutenção e desenvolvimento capitalista, por que não o seria nas novas formas de acumulação do capital? É imprescindível destacar que o poder disciplinar, que é uma prática social, conforme aborda Foucault, é fundamental para a constituição da sociedade capitalista de maneira que, em suas palavras, “o poder não se dá, não se troca, nem se retoma, mas se exerce, só existe em ação" (FOUCAULT, 2013, p. 274).

Essa disciplina, infere Machado (2013, p. 21) "é uma técnica, um dispositivo, um mecanismo, um instrumento de poder", utilizada para o controle do corpo e da população. Segundo o autor, uma das características do poder disciplinar - a vigilância - é um dos principais instrumentos de controle:

Não uma vigilância que reconhecidamente se exerce de modo fragmentar e descontínuo; mas que é ou precisa ser vista pelos indivíduos que a ela estão expostos como contínua, perpétua em toda a extensão do espaço. [...]. Finalmente, a disciplina implica um registro contínuo de conhecimento. Ao mesmo tempo que exerce um poder, produz um saber. (MACHADO, 2013, p. 22-23) 
Ao discorrer sobre a avaliação no contexto escolar, Foucault (2012, p. 177) percebia o exame (prova de avaliação) como dispositivo de vigilância "que permite qualificar, classificar e punir. Estabelece sobre os indivíduos uma visibilidade através da qual eles são diferenciados e sancionados". A avaliação permite a seleção, a classificação e a hierarquização porque possibilita aos alunos serem vistos, vigiados e até punidos por meio do exame.

A avaliação que ultrapassa as paredes da sala de aula tem se configurado como política de Estado². Durli e Schneider (2011, p. 173), concordam que “o Estado exerce influência no currículo, na gestão escolar, na formação de professores, ou seja, sobre o conjunto de atores de sua ingerência" por intermédio da avaliação externa em larga escala, sendo um modo de regulação institucional.

Para além disso, a política avaliativa de caráter gerencialista, em que são utilizados instrumentos externos de larga escala, como dispositivos de poder e de vigilância constante, remete à prática de avaliação por comparação. Robertson (2012), coerentemente, faz analogia entre os benchmarks e rankings com o uso de aviões não tripulados (drones) que, a distância, coletam dados para promover ações táticas e estratégicas no campo visado. Consoante à autora,

Como aviões não tripulados, essas tecnologias globais são capazes, ao longo do tempo, de coletar suficientemente os dados precisos de um terreno e de sua topografia e usar essas informações para preparar uma ação. Contudo, como qualquer sistema de posicionamento global (GPS) que dirige as ações dos aviões não-tripulados, não pode enxergar suficientemente os detalhes que fazem a diferença. Além disso, aqueles que estão por trás da tecnologia frequentemente estão muito afastados das consequências de suas atividades onde danos colaterais e desastres políticos são lembranças úteis da necessidade de cautelas políticas. (ROBERTSON, 2012, p. 22)

Por intermédio da avaliação baseada em benchmarking, o Estado regula as políticas educacionais e controla remotamente os agentes educacionais. Enquanto mecanismo de controle, a avaliação coleta dados e informações afastada das escolas, dos

\footnotetext{
${ }^{2}$ A Portaria $n^{\circ} 458$, de 5 de maio de 2020, estabelece que a Política Nacional de Avaliação da Educação Básica, envolve o Sistema de Avaliação da Educação Básica (Saeb); o Exame Nacional para a Certificação de Competências de Jovens e Adultos (Encceja); e, o Exame Nacional do Ensino Médio (Enem), realizados anualmente. (BRASIL, 2020).
} 
professores, dos alunos, da comunidade escolar, desconsiderando as especificidades do local e ignorando as particularidades dos agentes.

A avaliação, ao ter em vista o alcance das metas do Índice de Desenvolvimento da Educação Básica (Ideb), produz um saber e uma ação que podem desconsiderar os agentes envolvidos diretamente com a educação, mas também subestima os danos colaterais consequentes dessa política. Para Freitas (2012), efetuar sem evidência empírica uma política pública,

[...] mais do que gastar dinheiro inadequadamente, caracteriza violação da ética já que não se devem fazer experimentos sociais com ideias pouco consolidadas pela evidência empírica disponível. A avaliação mexe com a vida de alunos, professores, pais e gestores. (FREITAS, 2012, p. 386)

Os danos colaterais começam pelo que Freitas (2012) chama de estreitamento curricular. As avaliações externas em larga escala no Brasil avaliam o desempenho dos alunos 3 tendo como objetivo a boa performance dos alunos nas provas. Segundo o autor, as provas tendem a olvidar dimensões que envolvem a criatividade, o desenvolvimento corporal, as artes, dentre outros. O denominado conhecimento básico se refere ao conhecimento mínimo (FREITAS, 2012).

Tendo por base Freitas (2012), a fraude e o aumento da segregação socioeconômica dentro da escola e no território também são danos colaterais das avaliações. Ou seja, nas palavras de Freitas (2012, p. 393), “[...] as pressões sobre o professor terminam obrigando-o a segregar os alunos que estão nas pontas dos desempenhos (mais altos e mais baixos) e concentrar-se no centro, em especial naqueles que estão próximos da média". Consequentemente, promovem uma seleção já na matrícula, pois alunos com histórico escolar de risco, supostamente, poderiam comprometer o resultado do Ideb da instituição. Assim, acabariam por ter suas matrículas não aceitas ou não homologadas em determinadas escolas.

Neste sentido, a avaliação que envolve benchmarkings e rankings, semelhante aos drones, mais do que a vigilância constante e a distância que pune, diz respeito à

\footnotetext{
3 A Prova Brasil, por exemplo, realizada a cada dois anos, avalia as habilidades dos alunos em Língua Portuguesa e Matemática (DURLI; SCHNEIDER, 2011).
} 
[...] incerteza de ser julgado de diferentes maneiras por diferentes meios, através de diferentes agentes e agências e a exigência de termos de mostrar desempenhos excelentes, ou pelo menos credíveis, colectiva ou individualmente, em momentos de revisão, avaliação/apreciação e inspeção. (BALL, 2002, p. 9-10)

A vigilância constante leva a uma insegurança permanente. A todo momento os alunos devem mostrar e provar sua "competência” nas avaliações. Os docentes também devem expressar sua boa performance mediante o desempenho de seus alunos. Se o estudante aprendeu, o responsável é o professor, se não aprendeu, a responsabilidade também é sua. Assim, a partir de um saber produzido pela avaliação, promove-se uma ação, a forma accountability4. A propósito, de acordo com Azevedo,

o trabalho docente [...] tem sido objeto de avaliação e parametrização não só nacional, mas transnacional. Exemplo neste sentido pode ser notado nas atividades do Departamento de Desenvolvimento Humano do Banco Mundial (BM) que lançou o programa SABER - Teachers (System Assessment and Benchmarking for Education Results) ${ }^{5}$, que tem por metodologia de avaliação, conforme sugere a denominação, instrumentos referenciados em benchmarking. (AZEVEDO, 2016, p. 14091410)

Prestar contas e fazer com que todos se sintam responsáveis por uma boa educação é importante e democrático. O problema é quando a responsabilização e a prestação de contas estão atreladas à avaliação. Enquanto o Estado se desresponsabiliza pelos resultados, a escola e, principalmente, gestores e professores são os responsáveis, seja pelo êxito ou pelo fracasso do "produto".

Freitas (2012) indica que a responsabilização envolve as provas para os estudantes, divulgação pública do desempenho, recompensas e sanções. Exames para estudantes já são uma política educacional, a divulgação do desempenho, em forma de rankings é uma prática consolidada pela mídia. Bonificações e premiações baseadas nas avaliações são realizadas. Mas há preocupação com o que propagam as agências internacionais como o Banco Mundial.

\footnotetext{
4 De acordo com Afonso (2012), accountability diz respeito a uma forma gerencialista de prestação de contas em que dá destaque a consequências negativas e à responsabilização de instituições e indivíduos.

${ }^{5}$ O Banco Mundial, recentemente, mudou o nome do programa para Systems Approach for Better Education Results (SABER) (WORLD BANK, 05 Mar. 2020).
} 
Segundo Robertson (2012), o Banco Mundial recomenda que o pagamento de professores deve ser condicionado ao desempenho dos estudantes nas avaliações. $O$ Banco Mundial assinala que, para os problemas de reprovação de alunos e de aprendizagem,

\begin{abstract}
A solução almejada é que os professores devem ser pagos não pelo reconhecimento formal das qualificações por tipo de serviço, locação geográfica ou outros modos. Pelo contrário, devem ser contratados (com períodos específicos de emprego) com pagamento sujeito ao desempenho dos estudantes para que se estabeleça uma ligação entre as condições do emprego dos professores e responsabilização pelos resultados. (ROBERTSON, 2012, p.17-18)
\end{abstract}

Ao tratar do assunto, Robertson (2012) aponta que o argumento do Banco Mundial é que os sistemas de ensino contam com profissionais com estabilidade no emprego e salários fixos, que além de não contribuir com esforços extras, não punem pelo desempenho ineficaz. É a lógica do mercado na governança educacional.

Como a governança educacional não se limita aos Estados, as Organizações Internacionais (OIs), em uma escala global buscam, por meio dos exames, estabelecer e formatar as políticas voltadas aos professores com base em indicadores de performance e manuais de "boas práticas" (Azevedo, 2016), consoante à perspectiva dessas mesmas Ols, tais como Banco Mundial, OCDE etc., que são evidenciadas nessas avaliações. O PNE 2014-2024 prescreve, por intermédio da Lei Federal n 13.005 (BRASIL, 2014), o uso de avaliação em larga escala, tendo por referência o PISA da OCDE, como estratégia de melhoria da qualidade da educação nacional. De acordo com Azevedo,

consignada no PNE no subitem 7.11, pretende-se que a qualidade da educação no Brasil avance, no decorrer dos anos de sua vigência, de 2014 a 2024, em comparação com outros países por intermédio de indicadores e da adoção de manuais de "boas práticas" propiciados e sistematizados pela OCDE, vale frisar, pela organização internacional mais conhecida no Brasil por ser a promotora do PISA. (AZEVEDO, 2016, p. 1.426)

Ao utilizar um método de comparação de desempenho e performance, responsabiliza-se o professor pelos resultados apresentados pelos alunos nas provas, isto é, vincula-se a performance dos alunos à performance do professor. Essa prática 
desconsidera que "as variáveis que afetam a aprendizagem do aluno não estão todas sob controle do professor" (FREITAS, 2012, p. 392).

No Brasil ${ }^{6}$, a responsabilização dos professores nesses moldes é a proposta dos reformadores empresariais que defendem a ideia de uma educação alinhada com a organização do setor privado, que premia as performances consoante os resultados (FREITAS, 2012). A estratégia 7.36 do Plano Nacional de Educação (PNE) assinala que é preciso "estabelecer políticas de estímulo às escolas que melhorarem o desempenho no Ideb, de modo a valorizar o mérito do corpo docente, da direção e da comunidade escolar" (BRASIL, 2014, p. 11). É a legitimação da política de premiações tendo por referência um índice medido por uma prova. Nessa direção, a política de avaliação como modo disciplinar atende aos propósitos neoliberais, pois, os

[...] dispositivos de recompensas e punições, sistemas de estímulo e desestímulo substituíram as sanções do mercado para guiar as escolhas e a conduta dos indivíduos quando as situações mercantis ou quase mercantis não são inteiramente realizáveis. [...] cuja pontuação condicionará a obtenção das recompensas e a evitação de punições. (DARDOT; LAVAL, 2016, p. 217)

A disciplina neoliberal pressupõe que esse tipo de política de recompensas e punições torne-se referência para a decisão individual, "para reforçar o desejo (pela recompensa), para enfraquecê-lo (pela punição), para desviá-lo (pela substituição do objeto" (DARDOT; LAVAL, 2016, p. 216). Desse modo, segundo os autores, recompensas e punições, como dispositivos de vigilância servem para orientar as escolhas e comportamentos dos indivíduos.

Nesse cenário, o esforço individual que é valorizado, seja do professor ou do aluno, e a avaliação servem como um mecanismo para recompensas ou sanções por meio de premiações, bonificações e para salários. O pagamento por mérito dos professores,

\footnotetext{
${ }^{6}$ Está em trâmite o Projeto de Lei do Senado n 116/2017, que dispõe sobre a perda de cargo público por insuficiência do servidor público estável. Dispondo sobre a avaliação periódica dos servidores públicos em todas as esferas federativas e sobre casos de exoneração por insuficiência de desempenho. (BRASIL, 2017). Disponível em: <https://www25.senado.leg.br/web/atividade/materias/-/materia/128876>. Acesso em: 20 jan. 2020.

7 A prefeitura de São Paulo anunciou a premiação para os professores e servidores que apresentaram resultados satisfatórios no ano de 2019. (CORDEIRO, 2019). Disponível em: $<$ https://educacao.estadao.com.br/noticias/geral,prefeitura-de-sp-anuncia-bonus-de-ate-r-5-mil-paraprofessores-e-servidores,70003138346>. Acesso em: 20 jan. 2020.
} 
expresso no desempenho dos alunos, é uma prática realizada nos Estados Unidos que não tem demonstrado bons resultados ${ }^{8}$.

A avaliação como instrumento do poder disciplinar é um mecanismo de punição. $O$ aluno é punido quando lhe é negado o acesso a um conhecimento em detrimento de outro, tendo em vista a preparação para as provas externas; quando é excluído antes ou depois de um exame que seleciona e classifica. O professor também é punido quando seus alunos não apresentam os resultados esperados. A avaliação, nesse sentido, pune; porém mais do que isso, ou por isso mesmo, pode modelar, fabricar o indivíduo.

\section{Avaliação para a performatividade}

É importante destacar que Michel Foucault não caracteriza o poder pela sua função repressiva ou coercitiva (MACHADO, 2013), mas assevera que seu objetivo é

[...] ao mesmo tempo econômico e político: aumento do efeito do trabalho, isto é, tornar os homens força de trabalho dando-lhes uma utilidade econômica máxima; diminuição de sua capacidade de revolta, de resistência, de luta, de insurreição contra as ordens do poder, neutralização dos efeitos de contrapoder, isto é, tornar os homens dóceis politicamente. Portanto, aumentar a utilidade econômica e diminuir os inconvenientes, os perigos políticos; aumentar a força econômica e diminuir a força política. (MACHADO, 2013, p. 20)

A disciplina neoliberal que estendeu e intensificou as lógicas de mercado, "tiveram efeitos muito patentes na organização do trabalho e nas formas de emprego da força de trabalho" (DARDOT; LAVAL, 2016, p. 225). É, nesse sentido, que a avaliação como dispositivo disciplinar, como mecanismo de recompensas e punições, pode ser também entendida como um instrumento de poder "subordinado às exigências da performatividade" (BALL, 2002, p. 19) que, para além de punir, formata os sujeitos. Essa tecnologia é uma forma de controle e, conforme Ball, é

[...], uma cultura e um modo de regulação que se serve de críticas, comparações e exposições como meios de controle, atrito e mudança. Os desempenhos (de sujeitos individuais ou de organizações) servem como medidas de produtividade e rendimento, ou mostras de qualidade

\footnotetext{
${ }^{8}$ Para saber mais, ver Freitas (2012) e Robertson (2012).
} 
ou ainda momentos de promoção ou inspecção. Significam, englobam e representam a validade, a qualidade ou valor de um indivíduo ou organização dentro de um determinado âmbito de julgamento/avaliação. (BALL, 2002, p. 4, grifo do autor)

\section{Ainda em consonância com o autor,}

A performatividade é alcançada mediante a construção e publicação de informações e de indicadores, além de outras realizações e materiais institucionais de caráter promocional, como mecanismos para estimular, julgar e comparar profissionais em termos de resultados: a tendência para nomear, diferenciar e classificar. (BALL, 2005, p. 544)

Aplicada à educação, a performatividade representa o valor de indivíduos ou instituições que, no âmbito da avaliação com base objetivista, mede, compara, hierarquiza e divulga a performance, que é "a medida de produtividade e desempenho" (BALL, 2010, p. 37) dos agentes educacionais, das escolas, das redes e até de países. A avaliação subordinada às exigências da performatividade aumenta a força econômica e diminui a força política.

É este o princípio da gestão neoliberal, "fazer os assalariados interiorizarem as novas normas de eficiência produtiva e desempenho individual" (DARDOT; LAVAL, 2016, p. 226). No campo da educação, os agentes educacionais, tendo em vista um bom desempenho dos alunos nas avaliações externas em larga escala, agem guiados pelos resultados. Ademais, os mecanismos de recompensas e sanções promovem a lógica concorrencial na educação.

A reforma, além das mudanças estruturais, muda atitudes e comportamentos, reforma professores e o que significa ser professor. A avaliação torna-se um instrumento que faz isso à distância (BALL, 2002). Segundo o autor,

[...] nós nos tornamos mais capazes, mais eficientes, mais produtivos, mais relevantes; nós nos tornamos fáceis de usar; nós nos tornamos parte da economia do conhecimento. Nós aprendemos que nós podemos ser mais do que já fomos. Existe algo muito sedutor em ser adequadamente apaixonado pela excelência, em conquistar o pico da performance. (BALL, 2010, p. 45, grifo do autor) 
Os mecanismos de medição, classificação e publicização utilizados na política de avaliação, ao colaborarem para a comparação, competitividade, individualismo e meritocracia, podem possibilitar o aumento da força econômica, elevando a produtividade. Esses mesmos mecanismos, todavia, contribuem para diminuir a força política, reduzindo a participação, o diálogo, o debate e inibem a solidariedade, o respeito e o exercício do trabalho coletivo.

A política de avaliação baseada nos exames estandardizados, cujos resultados são divulgados e hierarquizados publicamente, induz a performatividade dos professores. Quando os resultados são insatisfatórios, o docente muda/reduz o conteúdo, altera sua prática, com a finalidade de melhorar a performance dos estudantes. Afinal, o professor eficiente consegue ensinar o que é preciso para as avaliações (BALL, 2002). Além das mudanças concretas, de conteúdos e práticas,

as avaliações externas, portanto, têm consequências não controladas dentro das escolas e suas salas de aula e constituem parte de uma cadeia de ações que afeta a vida de professores, estudantes, diretores e pais de alunos. Neste processo rompem-se importantes pressupostos da relação e da confiança entre profissionais e entre estes e seus estudantes. (FREITAS, 2014, p. 1098)

E ainda,

Novos papéis e subjetividades são produzidos à medida que os professores são transformados em produtores/fornecedores, empresários da educação e administradores, e ficam sujeitos à avaliação e análise periódica e a comparação de desempenhos. Novas formas de disciplina são instituídas pela competição, eficiência e produtividade. (BALL, 2005, p. 546-547)

A Prova Brasil é um exemplo de avaliação que altera o cotidiano escolar e o ser professor. Segundo Durli e Schneider (2011), ela é um instrumento de regulação sobre o currículo escolar, ao passo que reúne vários elementos que influenciam o currículo das escolas, como os procedimentos de seleção; agrupamento dos conhecimentos e das metodologias, mas que também envolvem os componentes sociais.

O apelo discursivo utilizado para o "chamamento da escola à adesão e à participação, a divulgação comparativa dos resultados [...], a responsabilização do 
professor pelos baixos desempenhos [...], funcionam como fatores coercitivos na (re)organização dos currículos escolares" (DURLI; SCHNEIDER, 2011, p. 175). Isso tende a alterar também o trabalho do professor, e, por conseguinte, afetar sua subjetividade.

Nesse cenário, o professor passa a ser "definido pela flexibilidade, transparência, falta de profundidade [...], é concebido como simplesmente aquele que responde aos requisitos externos e a objetivos específicos" (BALL, 2005, p. 558). Assim, o professor tende a refrear a reflexão, não produzindo, mas reproduzindo as chamadas "boas práticas" a fim de atingir as metas estabelecidas heteronomamente, pois, conforme Ball (2005, p. 542), “o que conta como prática profissional resume-se em satisfazer julgamentos fixos e impostos a partir de fora. Os critérios de qualidade ou de boa prática são fechados e completos".

Docentes e estudantes são trespassados pela lógica performatividade por intermédio da avaliação. Aliás, toda instituição escolar é perpassada pela “cultura” performativa. Assim, alteram-se o currículo, o cotidiano escolar, e tendo em vista o bom desempenho e a boa performance, as notas e os índices se tornam o objetivo de professores, alunos, pais e gestores.

A política de avaliação, consoante à perspectiva adotada, priorizando a avaliação externa em larga escala, contribui para a consolidação de uma lógica competitiva no campo educacional. Concorre-se por melhores resultados, melhores notas e também há competição pela preferência das famílias (FALABELLA, 2014). Além de mudar a prática escolar, essa política altera de forma profunda e complexa o cotidiano escolar, a ética e as subjetividades da profissão docente (FALABELLA, 2014).

De acordo com a razão da performatividade, supostamente, como sentido de contribuir para aumentar a produtividade e, consequentemente, as forças econômicas, a avaliação possibilita também reduzir as forças políticas dos agentes envolvidos com a educação. "No âmbito de uma matriz de avaliações, comparações e incentivos relacionados com o desempenho, os indivíduos e as organizações farão o que for necessário para se distinguir ou sobreviver" (BALL, 2005, p. 549). Entra-se no jogo e esse modo de gerenciar por resultados, intermediado pela avaliação, envolve a responsabilização, a meritocracia, a privatização, a performatividade. É a meta-regulação pelo Estado, um hipergerencialismo. 


\section{Considerações finais}

A avaliação com um caráter economicista e mercadológico, ao atender os propósitos do Estado torna-se uma ferramenta de controle e regulação que pune e formata os agentes sociais. Dentre os efeitos punitivos dessa política, salientamos a redução curricular e de salários; a exclusão; a seleção, que elitiza e marginaliza; e, a exposição indevida dos agentes educacionais.

A performatividade é outro efeito da avaliação como instrumento de controle e regulação. Mais que punir, colabora para aumentar a competitividade, a produtividade, medindo a performance e o desempenho dos agentes e instituições educacionais. A avaliação, nesse sentido, corrompe a solidariedade e promove o individualismo, induzindo a não participação, reduzindo o diálogo, a atuação dos agentes no campo educacional, alterando a subjetividade e promovendo um novo habitus nos agentes sociais, que passam a pautar suas ações com base nas performances esperadas.

O conceito de violência simbólica de Pierre Bourdieu (2008) expressa os efeitos dessa política de avaliação, ao passo que, "a violência simbólica é desenvolvida pelas instituições e pelos agentes que as animam e sobre a qual se apóia o exercício da autoridade" (VASCONCELOS, 2002, p. 80).

A ênfase nos resultados que se tornam produtos atende aos interesses do mercado e colabora com sua expansão; se torna uma referência de escolha para clientes e consumidores. Esse instrumento, benchmarking, contribui para que a avaliação se constitua um mecanismo de prestação e responsabilização dos agentes educacionais junto ao Estado, especialmente quando os objetivos não são atingidos. Entretanto, o destaque para os resultados serve aos interesses do mercado, porque se assemelham a produtos, uma referência de escolha para clientes e consumidores. 


\section{Referências}

AFONSO, Almerindo Janela. Estado, políticas educacionais e obsessão avaliativa.

Contrapontos, Itajaí, v. 7, n. 1, p. 11-22, jan./abr. 2007.

AFONSO, Almerindo Janela. Para uma conceitualização alternativa de accountability em educação. Educação \& Sociedade, Campinas, v. 33, n. 119, p. 471-484, abr./jun. 2012.

AZEVEDO, Mário Luiz Neves de. A “Escola Cooperativa de Maringá” ou uma escola com "Ensino Público Gratuito com Microgestão Privada” (1991-1992): uma experiência de Charter School no Brasil avant la lettre. Arquivos Analíticos de Políticas Educativas, Tempe, v. 26, n.132, 2018. Disponível em: http://dx.doi.org/10.14507/epaa.26.2712. Acesso em: 16 jan. 2020.

AZEVEDO, Mário Luiz Neves de. Educação e benchmarking: meta-regulação e coordenação de políticas baseadas em indicadores e nas chamadas 'boas práticas'. In: SEMINÁRIO NACIONAL UNIVERSITAS/BR, 24. 2016. Maringá. Anais [...]. Maringá: Universidade Estadual de Maringá, 2016. p. 1407-1442. Disponível em: http://www.ppe.uem.br/xxivuniversitas/anais/trabalhos/e_6/6-008.pdf. Acesso em: 16 jan. 2020.

BALL, Stephen J. Reformar escolas/reformar professores e os terrores da performatividade. Revista Portuguesa de Educação, Braga, v. 15, n. 2, p. 3-23, 2002.

BALL, Stephen. J. Profissionalismo, gerencialismo e performatividade. Cadernos de Pesquisa, São Paulo, v. 35, n. 126, p. 539-564, set./dez. 2005.

BALL, Stephen J. Performatividade e fabricações na economia educacional: rumo a uma sociedade performativa. Educação \& Realidade, Porto Alegre, v. 35, p. 37-55, maio/ago. 2010.

BOURDIEU, P.; PASSERON, J-C. A reprodução: elementos para uma teoria do sistema de ensino. Petrópolis: Vozes, 2008.

BRASIL, Plano Nacional de Educação (PNE). Lei no 13.005, de 25 de junho de 2014. Aprova o Plano Nacional de Educação - PNE e dá outras providências. Brasília, DF. 2014.

BRASIL, Portaria $n^{\circ} 458$, de 5 de maio de 2020. Institui normas complementares necessárias ao cumprimento da Política Nacional de Avaliação da Educação Básica. Diário Oficial da União. Seção 1, Brasília, DF, p. 57, 2020. Disponível em:

https://www.in.gov.br/web/dou/-/portaria-n-458-de-5-de-maio-de-2020-255378342. Acesso 27 mar. 2020.

BRASIL. Senado Federal. Projeto de Lei do Senado n 116, de 2017 (Complementar). Regulamenta o art. $41, \S 1^{\circ}$, III, da Constituição Federal, para dispor sobre a perda do cargo público por insuficiência de desempenho do servidor público estável. Brasília, DF: Senado 
Federal, 2017. Disponível em: https://www25.senado.leg.br/web/atividade/materias//materia/128876. Acesso em 20 jan. 2021.

CORDEIRO, FELIPE. Prefeitura de SP anuncia bônus de até R\$ 5 mil para professores e servidores. O Estado de São Paulo. São Paulo, 28 de dezembro de 2019. Disponível em: https://educacao.estadao.com.br/noticias/geral,prefeitura-de-sp-anuncia-bonus-de-ate-r5-mil-para-professores-e-servidores,70003138346. Acesso em: 20 jan. 2020.

DALE, Roger. A sociologia da educação e o Estado após a globalização. Educação \& Sociedade, Campinas, v. 31, n. 113, p. 1099-1120, out./dez. 2010.

DANNER, Fernando. O sentido da Biopolítica em Michel Foucault. Revista Estudos Filosóficos, São João del-Rey, n. 4, p. 143-157, 2010.

DARDOT, Pierre; LAVAL, Christian. A nova razão do mundo: ensaio sobre a sociedade neoliberal. 1. ed. São Paulo: Boitempo, 2016.

DURLI, Zenilde; SCHNEIDER, Marilda Pasqual. Regulação do currículo no ensino fundamental de 9 anos. Revista Contrapontos - Eletrônica, Itajaí, v. 11, n. 2, p. 170-178, maio/ago. 2011.

FALABELLA, Alejandra. The performing school: the effects of market policies \& accountability. Education policy analysis archives, Arizona, v. 22, n. 70, p. 1-29, 2014.

FOUCAULT, Michel. História da sexualidade I: a vontade de saber. 6. ed. Rio de Janeiro: Graal, 1985.

FOUCAULT, Michel. Microfísica do poder. 27. ed. São Paulo: Graal, 2013.

FOUCAULT, Michel. Nascimento da Biopolítica: curso dado no Collége de France (19781979). São Paulo: Martins Fontes, 2008.

FOUCAULT, Michel. Vigiar e punir: nascimento da prisão. 40. ed. Petrópolis: Vozes, 2012.

FREITAS, Luiz Carlos de et. al. Avaliação educacional: caminhando pela contramão. 2. ed. Petrópolis: Vozes, 2009.

FREITAS, Luiz Carlos de. Os reformadores empresariais da educação: Da desmoralização do magistério à destruição do sistema público de educação. Educação \& Sociedade, Campinas, v. 33, n. 119, p. 379-404, abr./jun. 2012.

FREITAS, Luiz Carlos de. Os reformadores empresariais da educação e a disputa pelo controle do processo pedagógico na escola. Educação \& Sociedade, Campinas, v. 35, n. 129, p. 1085-1114, out./dez. 2014.

HOOD, Christopher. A public management for all seasons? Public Administration, San Diego, v. 69, p. 3-19, spring 1991. 
MACHADO, Roberto. Introdução: por uma genealogia do poder. In: FOUCAULT, Michel.

Microfísica do poder. 27. ed. São Paulo: Graal, 2013. p. 7-34.

ROBERTSON, Susan L. "Situando" os professores nas agendas globais de governança.

Revista Teoria e Prática da Educação, Maringá, v. 15, n. 2, p. 09-24, maio/ago. 2012.

VASCONCELOS, Maria Drosila. Pierre Bourdieu: a herança sociológica. Educação \& Sociedade, Campinas, ano 23, n. 78, p. 77-87, abr. 2002.

WORLD BANK. Systems Approach for Better Education Results (SABER). The World Bank Group. [Whasington: The World Bank, c2021]. Disponível em: http://saber.worldbank.org/index.cfm. Acesso em: 5 mar. 2020.

Universidade do Estado de Santa Catarina - UDESC Programa de Pós-Graduação em Educação - PPGE 